Research Paper

\title{
Lin28b is involved in curcumin-reversed paclitaxel chemoresistance and associated with poor prognosis in hepatocellular carcinoma
}

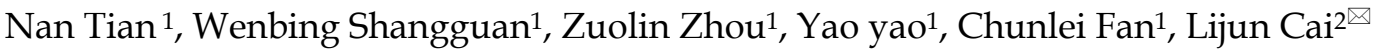 \\ 1. Institute of Molecular Medicine, Life Science College, Zhejiang Chinese Medical University, Hangzhou, Zhejiang, China \\ 2. Department of gastroenterology, the First Affiliated Hospital of Zhejiang Chinese Medical University, Hangzhou, Zhejiang, China \\ $\triangle$ Corresponding author: Lijun Cai, Address: Department of gastroenterology, the First Affiliated Hospital of Zhejiang Chinese Medical University 54 Youdian \\ Road, Hangzhou. Zhejiang Province. P. R. China. Tel.: +86(571) 86620285; Fax: +86(571) 87077785
}

(C) The author(s). This is an open access article distributed under the terms of the Creative Commons Attribution License (https://creativecommons.org/licenses/by/4.0/). See http:/ /ivyspring.com/terms for full terms and conditions.

Received: 2019.01.23; Accepted: 2019.08.24; Published: 2019.10.15

\begin{abstract}
Chemoresistance remains a big challenge in hepatocellular carcinoma $(\mathrm{HCC})$ treatment. Several studies indicated that RNA-binding protein Lin28B serves an oncogenic role in HCC, but its activity in HCC chemotherapy has never been assessed. In this study, we found that overexpression of Lin28B significantly increased the paclitaxel chemoresistance in two different $\mathrm{HCC}$ cells lines while silencing Lin28B reduced the chemoresistance in paclitaxel-resistance HCC cells. Curcumin, a natural anti-cancer agent, increased the sensitivity of HCC cells to paclitaxel through inhibiting NF-KB stimulated Lin28B expression both in vitro and in vivo. Furthermore, by analyzing TCGA (The Cancer Genome Atlas) LIHC (liver hepatocellular carcinoma) and GSE 14520 databases, we found that Lin28B was highly upregulated in HCC tissue compared with that in normal tissue and associated with $\alpha$-fetoprotein levels, and that patients with Lin28B higher expression had a significant shorter overall survival time than those with Lin28B lower expression. Our data reveal that Lin28B may serve as a predictive biomarker and a treatment target to reverse $\mathrm{HCC}$ chemotherapy resistance in future clinical practice.
\end{abstract}

Key words: curcumin, chemoresistance, Lin28B, NF-kB, hepatocellular carcinoma

\section{Introduction}

Hepatocellular carcinoma (HCC) is one of the most common solid-organ malignancies worldwide and it is particularly prevalent in China. Approximately 600,000 new cases of HCC are diagnosed every year, and $43 \%$ of them occur in China $[1,2]$. Because of the insidious onset of HCC and the lack of symptoms in the early stage of the disease, only 10 to $20 \%$ of HCC tumors can be surgically excised. Therefore, for most cases of HCC, chemotherapy is the main treatment strategy [3]. However, hepatoma cells are known to be highly resistant to chemotherapeutic drugs, including paclitaxel [4-7]. Chemoresistance has become a major obstacle in the treatment of $\mathrm{HCC}$, clarifying the molecular mechanisms of drug resistance in HCC is important for developing more effective therapeutic approaches.
Mammalian genomes encode two evolutionarily conserved and developmentally regulated RNAbinding proteins, Lin28A and Lin28B, which are master regulators of the let-7 family of microRNAs [8, 9]. Lin28A and Lin28B regulate let-7 microRNAs by binding to the terminal loop of the miRNA precursors and blocking their biogenesis, resulting in derepression of let- targets, such as cell cycle proteins, cyclin-dependent kinases, growth factors, and ribosomal proteins [10]. The expression levels of these two Lin28 homologues are significantly downregulated during cellular differentiation, and they are thought to be involved in tumorigenesis. They may also regulate the pluripotency of embryonic stem (ES) cells [11-13], and combined with pluripotency factors such as octamer-binding transcription factor 4 (Oct4), Nanog, sex determining region $Y$ box 2 (Sox2), Lin28A 
can assist in reprogramming somatic cells to pluripotent stem cells $[13,14]$.

Lin28B was first cloned from and was shown to be overexpressed in human HCC cells and clinical samples [15], and it functions as an oncogene by promoting malignant transformation [16, 17], facilitating tumor-associated inflammation [18, 19], reprogramming metabolism, acquiring immortality, and evading immune destruction [20]. Mice overexpressing Lin $28 B$ develop multiple tumors, including lymphoma, neuroblastoma, colonic adenocarcinoma, Wilms' tumor, hepatoblastoma, and HCC [21-25], suggesting that $\operatorname{Lin} 28 B$ alone is sufficient to drive cancer. Furthermore, clinical epidemiological studies have indicated that Lin28B is associated with both susceptibility to certain cancers and overall survival in cancer patients [26-28]. Lin28B is involved in the maintenance of liver cancer through several ways like downregulating the expression of anti-onco-miRNAs [29, 30] and promoting Sp-1/c-Myc [31]. However, the impact of Lin28B in HCC chemotherapy is unknown.

Curcumin, the golden nutraceutical derived from the roots of Curcuma longa Linn., has been reported to possess anti-cancer property against several tumor types, including $\operatorname{HCC}[32,33]$. It has been used to suppress inflammation, induce apoptosis, reduce tumor invasion and angiogenesis, and reverse drug resistance. Our previous experiments showed that curcumin sensitized HCC cells to the therapeutic agent paclitaxel. Therefore, in the current study, we generated a Lin28B-overexpresison cell line, a paclitaxel-resistant HCC cell line and a xenograft tumor model to explore whether Lin28B contributes to chemoresistance in HCC, and explore the underlying mechanism by which curcumin reverses paclitaxel resistance in HCC cells. Moreover, we used two independent Liver Hepatocellular Carcinoma gene expression datasets to evaluate the potential clinical value of Lin28B in HCC.

\section{Materials and Methods}

\section{Cell lines and compounds}

The human hepatoma cell line Hep3B, HepG2 were obtained from Cell Resource Center of Shanghai Institute of Life Sciences and grown in Dulbecco's modified Eagle's medium (DMEM) supplemented with $10 \%$ fetal calf serum (FBS), penicillin $(100 \mathrm{U} / \mathrm{mL})$ and streptomycin $(100 \mathrm{mg} / \mathrm{mL})$ at $37^{\circ} \mathrm{C}$ in $5 \% \mathrm{CO}_{2}$. Paclitaxel and curcumin were purchased from Tianjin Yi Fang Science and Technology, Ltd., (Tianjin, China), and dissolved in dimethyl sulfoxide (DMSO), stored at $-20^{\circ} \mathrm{C}$ and diluted in cell culture medium immediately prior to use.

\section{Human tissue samples}

HCC gene expression datasets are deposited at NCBI's Gene Expression Omnibus (GEO) public database (http://www.ncbi.nlm.nih.gov/geo/, GEO accession number, GSE41804) and The Cancer Genome Atlas Liver Hepatocellular Carcinoma (https://cancergenome.nih.gov/, TCGA-LIHC). GSE 41804 contains 40 samples including 20 pairs of fresh HCC specimens and their corresponding adjacent non-tumor. TCGA-LIHC dataset contains 377 HCC cases and comprises follow-up information for patients and gene expression data. Patients with available data on Lin28B expression and follow-up information were included into the present study. Correlations of Lin28B expression with the clinicopathological features, overall survival (OS) and progression-free survival (PFS) of patients with HCC were analyzed. Patients were organized according to their Lin28B expression levels from low to high expression, and then divided into two groups by median Lin28B expression. OS was defined as the period from the date of the pathological diagnosis to death; PFS was defined as the period from the date of the initial treatment to HCC progression, presenting as new tumor event.

\section{Development of a paclitaxel-resistant cell line (Hep3B/TAX)}

To develop a paclitaxel-resistant HCC cell line, Hep3B cells were exposed to gradually increasing concentrations of paclitaxel $(0.01-0.2 \mu \mathrm{M})$ in complete medium. Briefly, Hep3B cells were seeded in culture flasks at a density of $4 \sim 5 \times 10^{5}$ cells $/ \mathrm{mL}$ and allowed to grow. After $24 \mathrm{~h}$ incubation, paclitaxel $(0.01 \mu \mathrm{M})$ was added, and the cells were incubated for another $24 \mathrm{~h}$. Then, the cells were washed 3 times with D-Hanks solution and the medium was changed to paclitaxel-free medium. The cells were incubated and allowed to grow until confluent. Then, the cells were subcultured and re-exposed to double the dose of drug. This process was repeated until the cells were resistant to $0.2 \mu \mathrm{M}$ paclitaxel. After successful development, Hep3B/TAX cells were maintained in complete medium containing a low concentration of paclitaxel $(0.01 \mu \mathrm{M})$.

\section{Viability and apoptosis}

The cell viability was measured by MTT assay according to the manufacturer's protocol (Nanjing KeyGen Biotech. Co. Ltd., China). $5 \times 10^{3}$ cells were plated on 96-well plates and after overnight incubation treated with the indicated drugs for 48 hours. MTT solution $(5 \mathrm{mg} / \mathrm{mL})$ was added to each well and the plate was incubated for $4 \mathrm{~h}$ at $37^{\circ} \mathrm{C}$. After removal of the medium, formazan crystals were 
dissolved in $150 \mathrm{~mL}$ of DMSO. The absorbance of MTT-formazan was measured at $550 \mathrm{~nm}$ using a SpectraMaxM3 microplate reader (MolecularDevices, Sunnyvale, CA, USA). Apoptosis was assessed using Annexin V PE/7-AAD apoptosis assay (Nanjing KeyGen Biotech. Co. Ltd., China), stained cells were quantified using a Guava easyCyte 5 Flow Cytometer (EMD Millipore, USA).

\section{Isobologram analysis}

For combination assay, $\mathrm{IC}_{50}$ was calculated from two sets of concentration response graphs, the combination index $(\mathrm{CI})$ was calculated according to the following equation [34]: Sum CI $(\Sigma C \mathrm{CI})=\mathrm{IC}_{50}$ of A in mixture/ $\mathrm{IC}_{50}$ of $\mathrm{A}$ alone $+\mathrm{IC}_{50}$ of $\mathrm{B}$ in mixture/ $\mathrm{IC}_{50}$ of $\mathrm{B}$ alone. The $\mathrm{CI}$ values were defined as follows: $<1$, synergism; $=1$, additive; and $>1$, antagonism.

\section{RNA extraction and quantitative real-time PCR (qRT-PCR)}

Total RNA from the cells was extracted using Trizol reagent (Thermo Fisher Scientific, USA). qRT-PCR was performed with a HiFi-MMLV cDNA kit and UltraSYBR Mixture (Beijing ComWin Biotech Co., Ltd., Beijing, China). The primers used for qRTPCR to detect Lin28B (forward primer 5'-GACCCAA AGGGAAGACAC-3', reverse primer 5'-TCTTCCCTG AGAACTCGCGG-3') and $\beta$-actin (forward primer 5'-GGCACCACACCTTCTACAAT-3', reverse primer 5'-GTGGTGGTGAAGCTGTAGCC-3') were synthesized by Nanjing GenScript Co. Ltd., China. The fold-change of each gene was calculated using the $2^{-\Delta \Delta \mathrm{Ct}}$ method.

\section{Preparation of nuclear extracts}

Experiments were performed according to manufacturer's instructions (nuclear extraction kit; KeyGen Biotech, Nanjing, China). Protein concentration was determined using a Nanodrop ND-1000 Spectrophotometer (NanoDrop Technologies, Wilmington, DE). The nuclear extract was used for western blot analysis.

\section{Western blot analysis}

Whole cell lysates or tissues extracts were prepared using RIPA Lysis Buffer (Beyotime Biotechnology, China) containing PMSF Protease Inhibitor (Thermo Fisher Scientific, USA), separated by SDSPAGE and transferred onto PVDF Membrane (Merck Millipore, Germany). Membranes were probed with the indicated antibodies. Mouse polyclonal anti- $\beta$ actin antibody was purchased from HuaBio Biotechnology (Huabio, China), Rabbits polyclonal antibodys of NF- $\kappa \mathrm{B}$, caspase 9, caspase 3, Bcl-2, Histone H1 were purchased from Proteintech Group, and anti-Lin28B rabbit polyclonal antibody was purchased from
BBI Life Sciences Corporation. Immune complexes were detected using the enhanced chemiluminescence system (Advansta, Menlo Park, CA, USA).

\section{RNA interference}

The short interfering RNA (siRNA) strand oligomers specific for Lin28B and its negative control siRNA (si-NC) were synthesized by Biomics Biotechnologies Co., Ltd. (Nantong, China). Cells were plated in 6-well plates and incubated for $24 \mathrm{~h}$. Next, cells were transfected with siRNA using the Lipofectamin 2000 (Thermo Fisher Scientific, USA.) in accordance with the manufacturer's instructions. At $24 \mathrm{~h}$ after transfection, cells treated with or without paclitaxel for another $48 \mathrm{~h}$, then harvested and used for MTT assay.

\section{Establishment of Lin28B stable expression cell lines}

Cells were transfected with either pEnter or pEnter-Lin28B (Vigene Biosciences, China) using Lipofectamin 2000. After $72 \mathrm{~h}$ incubation, puromycin was then added to the transfected cells for generating cells stably overexpressing Lin28B. Lin28B stable expression cell lines were identified by western blot, and then used for the experiments.

\section{Mouse tumor xenografts}

BALB/c nude mice (male, 5-week-old, 16-20 g) were purchased from Shanghai Slack Laboratory Animal Co. Ltd. (animal license number: SCXK (Shanghai) 2012-0002). All procedures were performed with approval of and in accordance with the guidelines of the National Institutes of Health animal care committee. Hep3B/TAX cells were injected into the dorsal flanks of each mouse. After 14 days, the mice were randomly assigned to five groups $(n=5)$, and either treated with or without DMSO, curcumin $(40 \mathrm{mg} / \mathrm{kg})$, paclitaxel $(10 \mathrm{mg} / \mathrm{kg})$, or curcumin plus paclitaxel by intraperitoneal injections every 3 days, respectively. Tumor volume was calculated using the formula $\mathrm{V}=\mathrm{W}^{2} \times \mathrm{L} \times 0.5$. The mice were sacrificed and tumors were harvested for the follow-up experiments.

\section{Immunofluorescent staining (IF)}

Cells grown on glass coverslips were treated with different concentrations of curcumin $(0,5,10$, and $20 \mu \mathrm{M})$ for $4 \mathrm{~h}$ and then co-treated with $1 \mu \mathrm{M}$ paclitaxel for an additional $24 \mathrm{~h}$. After washing with PBS, slides were fixed with $4 \%$ paraformaldehyde. Then after washing with $5 \%$ Triton-X100 for $15 \mathrm{~min}$ at $25^{\circ} \mathrm{C}$, and slides were blocked with $5 \%$ BSA for $1 \mathrm{~h}$ and incubated with the NF- $\kappa$ B antibody overnight at $4^{\circ} \mathrm{C}$. Following incubation with goat anti-rabbit secondary antibody at $25^{\circ} \mathrm{C}$ for $2 \mathrm{~h}$, slides were 
incubated with SYBR-FITC (Boster Bioengineering, Wuhan, China) for $1 \mathrm{~h}$. Then DNA was counterstained with DAPI and images were captured with a Nikon ECLIPSE Ti-S microscope (Nikon, Japan).

\section{Immunohistochemistry (IHC)}

The dissected tumors sections $(5 \mu \mathrm{m})$ mounted on the glass slides were deparaffinized and rehydrated. Subsequently, the specimens were washed in $0.01 \mathrm{M}$ PBS, treated with 3\% hydrogen peroxide, and washed in $0.01 \mathrm{M}$ PBS again. Blocking was performed with $3 \%$ BSA in $0.01 \mathrm{M}$ PBS. Then the sections were incubated with antibodies for proliferation marker Ki-67 (Calbiochem, Cambridge, MA), Lin28B, and NF- $\mathrm{B}$, followed by incubation with secondary antibodies. After the cell nuclei were labeled with hematoxylin, images were captured using a microscope (XSP-C204, Chongqing Optical Instrument Co., Ltd.).

\section{NF-kB (p65) transcription factor assay}

NF- $\kappa$ B activity level was measured by evaluating NF- $\kappa B$ (p65) DNA binding activity in nuclear extracts of Hep3B/TAX cells. Analysis was performed following the manufacturer's protocol for NF- $\mathrm{BB}$ (p65) transcription Factor Assay Kit (Abnova, Germany). Cells were harvested and washed twice with PBS, 500 $\mathrm{mL}$ of cold hypotonic buffer supplemented with 0.5 $\mathrm{mL}$ of DTT, $5 \mathrm{~mL}$ of PMSF and $0.5 \mathrm{~mL}$ of protease inhibitor was added. Following centrifugation, the pellet containing the nuclear portion was then re-suspended in ice-cold complete nuclear extraction buffer and incubated on ice for $20 \mathrm{~min}$. The supernatant fractions were collected and added to the plate with transcription factor binding assay buffer. Following incubation with primary and secondary antibodies, color development was detected after addition of the developing solution. Finally, sample absorbance was measured at $450 \mathrm{~nm}$ using a SpectraMaxM3 microplate reader (MolecularDevices, Sunnyvale, CA, USA).

\section{Transient transfection and dual luciferase assay}

The pGL3-IRES-Lin28b-P3 plasmid that contains Lin28B gene promoter fragment was got form Addgene (\#64794, Cambridge, MA, USA) [19]. Then, the consensus NF-kB binding motif (GGGGCTTTC) of the pGL3-IRES-Lin28b-P3 was mutated to GGCGATT TT using QuickMutation Site-Directed Mutagenesis Kit (Beyotime, Shanghai, China) and confirmed by sequencing analysis (GeneScript,Nanjing, China). The pGL3-IRES-Lin28b-P3 plasmid was termed pGL3-Lin28B-wt and the mutated one was termed pGL3-Lin28B-mut in this paper. Cells were grown in 6-well plates to confluence, then transfected with vectors using Lipofectamine2000 (Invitrogen; Thermo Fisher Scientific, Inc.), according to the manufacturer's instructions. We performed dual luciferase assay by using a kit from Promega according to the manufacturer's instruction. Briefly, firefly and renilla activity were recorded by a FLUOstar Omega Plate Reader (BMG Labtech, Germany). The relative intensity of firefly luciferase of each sample was normalized to its renilla luciferase.

\section{Statistical analysis}

Statistical analysis was performed using Student's $t$-test for pairwise comparison, 1-way ANOVA test for multiple group comparisons. $p$-values < 0.05 were considered statistically significant. Results were presented as means \pm SD. Survival curves were constructed with the Kaplan-Meier method and analyzed using log-rank tests. The correlation between Lin28B expression and HCC clinicopathological features was analyzed using Pearson's chi-square test. Prognostic factors were examined with univariate and multivariate Cox regression models.

\section{Results}

\section{Increased Lin28B mRNA expression confers poor prognosis in HCC patients}

To investigate Lin28B mRNA expression in HCC, two independent liver hepatocellular carcinoma gene expression datasets (TCGA-LIHC and GSE418 04) were employed. As shown in Fig. 1A and 1B, HCC tissues showed significant higher $\operatorname{Lin} 28 B$ transcript levels than normal tissues in both datasets $(p<0.05)$. Next, we investigated the correlation between Lin28B expression and overall survival (OS) or progressionfree survival (PFS) of HCC patients using KaplanMeier survival curve with log-rank tests. The analysis of the TCGA-LIHC cohort data revealed that patients with high Lin28B expression in tumor tissues exhibited significantly shorter survival than patients with low Lin28B expression levels ( $p=0.046$; Fig. $1 C$ ). However, analysis of the TCGA-LIHC cohort revealed no correlation between Lin28B expression and PFS (Fig. 1D). These data indicate the potential clinical value of Lin28B in HCC.

\section{Lin28B may be a valuable prognostic marker for patients with HCC}

We evaluated the association between Lin28B expression and the clinicopathological features of patients with HCC by the Chi-square test to explore the potential oncogenic role of Lin28B in HCC. Statistical analysis of the TCGA-LIHC cohort indicated that Lin28B expression was positively 
associated with $\alpha$-fetoprotein (AFP) levels $(p=0.023$ ). However, no statistically significant correlation was observed between Lin28B and other tested clinicopathological features, such as sex, age, neoplasm grade, pathologic stage, and relapse (Table 1). Next, univariate and multivariate analyses were performed to estimate the prognostic variables of Lin28B in the patients included in the TCGA-LIHC. Univariate analysis indicated that Lin28B expression was significantly associated with OS (hazard ratio [HR], 1.377; $p=0.029 ; 95 \%$ confidence interval $[95 \% \mathrm{CI}]$, 1.033-1.826; Table 2). Multivariate analysis showed that Lin28B might be an independent prognostic factor for patients with $\mathrm{HCC}(\mathrm{HR}, 1.002$; 95\% CI, $1.001-1.002 ; p<0.001)$. These preliminarily results indicate that Lin28B may have potential clinical value as a predictive biomarker for OS in patients with HCC.

\section{Lin28B contributes to paclitaxel resistance in HCC cells}

To further assess the contribution of Lin28B to paclitaxel resistance, we first overexpressed Lin28B in Hep3B cells via stable transfection of pEnter-Lin28B and then measured the $\mathrm{IC}_{50}$ of paclitaxel. As shown in Fig.2A, the $\mathrm{IC}_{50}$ of paclitaxel was increased in Hep3B cells stably overexpressing Lin28B, and the drug resistance index (RI) was $61.7 \%$ higher in Lin28B-overexpression cells than in cells transfected with a control vector $(p<0.01)$. To confirm this finding, we next investigated the effect of Lin28B knockdown on paclitaxel resistance in Hep3B/TAX
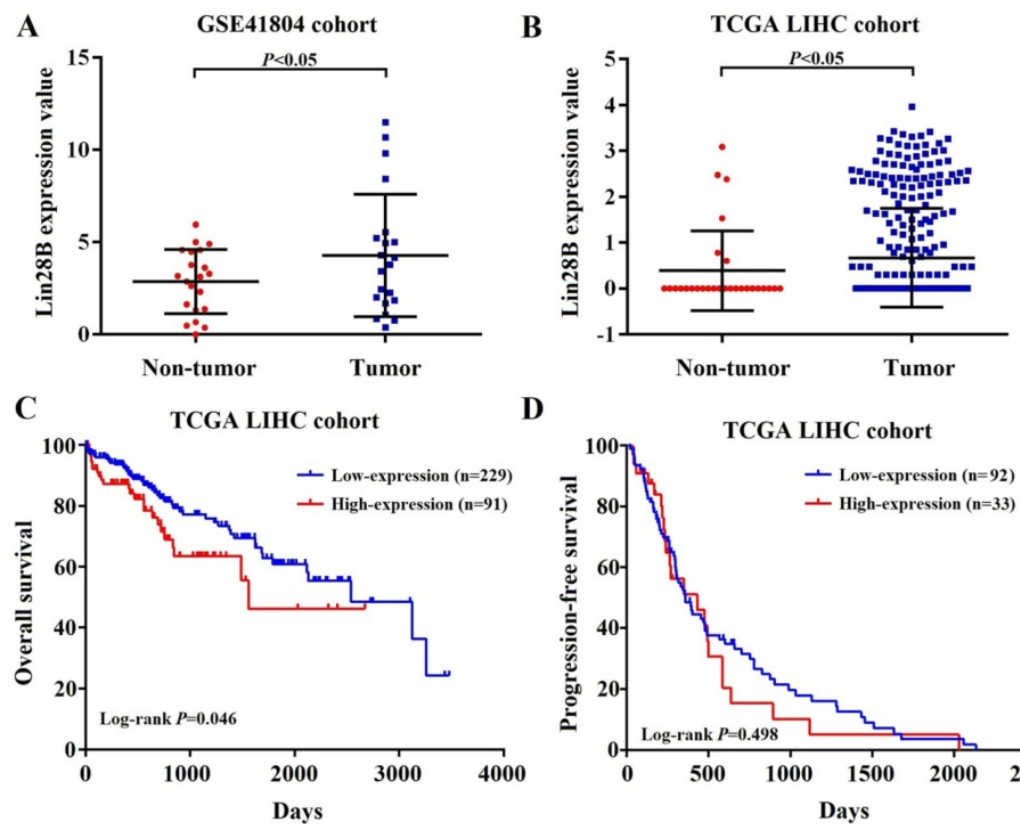

D

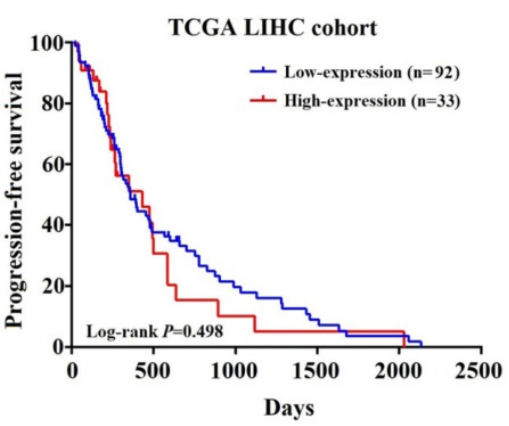

Figure 1. Increased Lin28B mRNA expression confers poor prognosis in patients with HCC. (A, B) Lin28B levels in the HCC tissues of patients in the GSE41804 and TCGA-LIHC datasets, respectively. Kaplan-Meier survival curve showing the (C) OS and (D) PFS rates in the TCGA-LIHC cohort. *p $<0.05$. cells following transient transfection of Lin28B siRNAs. The results showed that two siRNAs successfully knocked down Lin28B expression in Hep3B/TAX cells, and effectively reduced the paclitaxel $\mathrm{IC}_{50}$ (Fig. 2B). Accordingly, high Lin28B expression contributed to paclitaxel resistance in Hep3B/TAX cells as compared to the resistance of parental Hep3B cells.

To determine whether the contribution of Lin28B to paclitaxel resistance is specific to the Hep3B cell line, we investigated the effect of Lin28B on paclitaxel resistance in another HCC cell line, HepG2. We overexpressed Lin28B in HepG2 cells and determined the $\mathrm{IC}_{50}$ of paclitaxel by the MTT assay. The results showed that increased Lin28B expression significantly reduced the sensitivity of HepG2 cells to paclitaxel (Fig. 2C). Compared to the RI in cells transfected with a control vector, the RI in Lin28B-overexpression HepG2 cells was $11.2 \%$ higher $(p<0.01)$. These results suggest that the expression of Lin28B contributes to paclitaxel resistance in HCC cells and that this effect is not specific to the Hep3B cell line.

\section{Lin28B suppresses paclitaxel-induced apoptosis in HCC cells}

Paclitaxel has been shown to induce apoptosis in several cancer cells. Thus, we determined the effect of Lin28B on paclitaxel-induced apoptosis in HCC cells. Because Lin28B siRNA-2 was more efficient, we evaluated the apoptotic rate in Lin28B siRNA-2transfected Hep3B/ TAX cells treated with paclitaxel. Flow cytometry analysis showed that approximately $36.59 \pm 6.63 \%$ of the Lin28B-silenced cells underwent apoptosis after treatment with $0.1 \mu \mathrm{M}$ paclitaxel, which was significantly higher than that in the control and si-NC cells $(8.33 \pm 0.56 \%$ and $8.63 \pm 0.96 \%$, respectively; Fig. $3 \mathrm{~A})$. In contrast, Hep3B and HepG2 cells, stably overexpressing $\operatorname{Lin} 28 \mathrm{~B}$, were more resistant to paclitaxel-induced apoptosis, and Lin28B overexpression significantly reduced the number of apoptotic cells after paclitaxel treatment $(p<0.01$, Fig.3B $)$ compared to the empty-vector transfected cells. Furthermore, the activities of apoptosis-related proteins, which are commonly used as markers of apoptosis, were also detected. As shown in Fig.3C, Lin28B knockdown increased the cleavage of caspase 9 and 3 and reduced the expression of the anti-apoptotic protein Bcl-2 in Hep3B/TAX cells treated with $0.1 \mu \mathrm{M}$ paclitaxel, whereas Lin28B 
overexpression reduced the cleavage of caspase 9 and 3 and increased the expression of Bcl-2 in Hep3B and HepG2 cells, as compared to the levels in their respective control cells.

\section{Curcumin enhances paclitaxel-induced cytotoxicity and apoptosis in Hep3B/TAX cells}

The results of the MTT assay showed that curcumin suppressed Hep3B/TAX cells proliferation with an $\mathrm{IC}_{50}$ of $34.99 \pm 2.43 \mu \mathrm{M}$ (Fig. $4 \mathrm{~A}, \mathrm{IC}_{50}$ of paclitaxel is $5.65 \pm 0.51 \mu \mathrm{M}$ ). Therefore, we examined the effect of curcumin combined with paclitaxel at a series of concentrations lower than the $\mathrm{IC}_{50}$ to determine whether there is synergy between curcumin and paclitaxel. When combined with curcumin, the $\mathrm{IC}_{50}$ of paclitaxel in Hep3B/TAX cells was significantly decreased, in a dose-dependent manner. As shown in Fig.4B, when the concentration of curcumin was increased from 5 to $20 \mu \mathrm{M}$, the $\mathrm{IC}_{50}$ of paclitaxel decreased from 2.88 to $1.33 \mu \mathrm{M}$. Then, isobologram analysis was performed to evaluate the interaction between paclitaxel and curcumin. We found that the CI was considerably less than 1 when paclitaxel combined with curcumin, the CI was 0.65 for $2.88 \mu \mathrm{M}$ paclitaxel and $5 \mu \mathrm{M}$ curcumin, 0.66 for $2.09 \mu \mathrm{M}$ paclitaxel and $10 \mu \mathrm{M}$ curcumin, and 0.81 for $1.33 \mu \mathrm{M}$ paclitaxel and $20 \mu \mathrm{M}$ curcumin (Fig.4C). These results revealed that pretreatment of Hep3B/TAX cells with curcumin increased their sensitivity to paclitaxel.

The ability of curcumin to enhance paclitaxelinduced apoptosis in Hep3B/TAX cells was assessed by an apoptosis assay. Cells were treated with curcumin $(20 \mu \mathrm{M})$, paclitaxel $(1 \mu \mathrm{M})$, or co-treated with curcumin and paclitaxel for $48 \mathrm{~h}$, and then an Annexin V PE/7-AAD apoptosis assay was performed to determine the population of apoptotic cells. It was observed that the combination of paclitaxel and curcumin resulted in significantly higher cell death than single agent chemotherapy (Fig. 4D). While individual treatment with paclitaxel and curcumin led to $10 \%$ and $27 \%$ cell death, respectively, the combination of $1 \mu \mathrm{M}$ paclitaxel and $20 \mu \mathrm{M}$ curcumin resulted in nearly $34 \%$ cell death, and $2 \mu \mathrm{M}$ paclitaxel and $20 \mu \mathrm{M}$ curcumin resulted in $41 \%$ cell death. Moreover, paclitaxel-induced cleavage of caspase 9 and 3 was also increased by curcumin treatment, as shown in Fig.4E. Although individual treatment with $20 \mu \mathrm{M}$ curcumin or $1 \mu \mathrm{M}$ paclitaxel induced activation of caspase 9 and 3, combination chemotherapy increased the level of cleaved caspase in a dose-dependent manner. Taken together, these results indicate that curcumin sensitizes Hep3B/TAX cells to paclitaxel in vitro.

\section{Curcumin enhances paclitaxel-induced cytotoxicity and apoptosis in xenograft tumors}

Next, we sought to determine whether curcumin sensitizes HCC cells to paclitaxel in vivo. A subcutaneous xenograft model in nude mice was established using Hep3B/TAX cells, and then treated with curcumin $(40 \mathrm{mg} / \mathrm{kg})$, paclitaxel $(10 \mathrm{mg} / \mathrm{kg})$, or curcumin $(40 \mathrm{mg} / \mathrm{kg})$ and paclitaxel $(10 \mathrm{mg} / \mathrm{kg})$. The results demonstrated that the growth of tumor was significantly suppressed in mice co-treated with of curcumin and paclitaxel as compared to those in the control as well as in mice treated with either curcumin or paclitaxel alone (Fig. 5A and 5B). Tumors from co-treatment group showed decreased immunohistochemical (IHC) staining for Ki-67compared to the controls and individually treated tumors (Fig. 5D). Moreover, as shown in Fig.5C, the expression of apoptosis-related proteins was significantly reduced in tumors in the combination treatment group compared with the control and individually treated tumors. These results provide evidence that curcumin sensitized resistant HCC cells to paclitaxel in vivo.

Table 1. Correlation between Lin28B expression and HCC clinicopathological features in TCGA-LIHC

\begin{tabular}{|c|c|c|c|c|c|}
\hline \multirow[b]{2}{*}{ Variable } & \multirow{2}{*}{$\begin{array}{l}\text { Total, } \\
\text { n }\end{array}$} & \multicolumn{2}{|c|}{ Lin28B expression, $\mathbf{n}$} & \multirow{2}{*}{$\chi^{2}$} & \multirow{2}{*}{$\begin{array}{l}\text { P- } \\
\text { value }\end{array}$} \\
\hline & & Low & High & & \\
\hline Sex & 343 & & & 0.022 & 0.882 \\
\hline Male & 234 & 165 & 69 & & \\
\hline Female & 109 & 76 & 33 & & \\
\hline Age (years) & 342 & & & 2.84 & 0.092 \\
\hline$\leq 50$ & 74 & 58 & 16 & & \\
\hline$>50$ & 268 & 183 & 85 & & \\
\hline Family cancer history & 295 & & & 0.463 & 0.496 \\
\hline Yes & 94 & 70 & 24 & & \\
\hline No & 201 & 142 & 59 & & \\
\hline Lymphocyte infiltration & 214 & & & 0.785 & 0.675 \\
\hline None & 104 & 72 & 32 & & \\
\hline Mild & 93 & 69 & 24 & & \\
\hline Severe & 17 & 13 & 4 & & \\
\hline Vascular tumor cell invasion & 291 & & & 2.704 & 0.259 \\
\hline None & 190 & 139 & 51 & & \\
\hline Micro & 86 & 62 & 24 & & \\
\hline Macro & 15 & 8 & 7 & & \\
\hline Neoplasm grade & 340 & & & 1.059 & 0.303 \\
\hline $\mathrm{G} 1+\mathrm{G} 2$ & 214 & 154 & 60 & & \\
\hline G3+G4 & 126 & 84 & 42 & & \\
\hline Pathologic stage & 322 & & & 0.716 & 0.398 \\
\hline $\mathrm{I}+\mathrm{II}$ & 240 & 170 & 70 & & \\
\hline $\mathrm{III}+\mathrm{IV}$ & 82 & 34 & 28 & & \\
\hline AFP level (ng/ml) & 257 & & & 5.175 & $.023^{*}$ \\
\hline$<400$ & 197 & 148 & 49 & & \\
\hline$\geq 400$ & 60 & 36 & 24 & & \\
\hline Child-Pugh classification grade & 225 & & & 2.765 & 0.096 \\
\hline A & 206 & 148 & 58 & & \\
\hline $\mathrm{B}+\mathrm{C}$ & 19 & 17 & 2 & & \\
\hline Liver fibrosis Ishak score & 187 & & & 0.027 & 0.871 \\
\hline$\leq 4$ & 114 & 84 & 30 & & \\
\hline$>4$ & 73 & 53 & 20 & & \\
\hline Relapse & 258 & & & 0.809 & 0.368 \\
\hline Yes & 91 & 67 & 24 & & \\
\hline No & 167 & 114 & 53 & & \\
\hline
\end{tabular}




\section{Curcumin sensitizes HCC to paclitaxel by downregulating Lin28B and NF-KB}

To clarify the molecular mechanism by which curcumin reverses paclitaxel resistance in HCC cells, we first evaluated the expression of Lin28B in paclitaxel treated, and curcumin and paclitaxel co-treated Hep3B/TAX cells. As shown in Fig.6A and 6B, Lin28B expression was increased upon stimulation with paclitaxel; however, this increase was blocked by curcumin in a dose-dependent manner. Moreover, combined treatment with curcumin and paclitaxel downregulated the expression of Lin28B in the xenograft tumors (Fig. 5C and 5D), suggesting that the paclitaxel-induced increase in Lin28B expression was inhibited by curcumin.

Table 2. Univariate and multivariate analysis of prognostic factors in patients included in the TCGA-LIHC

\begin{tabular}{|c|c|c|c|c|c|c|}
\hline \multirow[b]{2}{*}{ Variable } & \multicolumn{3}{|c|}{ Univariate analysis } & \multicolumn{3}{|c|}{ Multivariate analyses } \\
\hline & HR & $95 \% \mathrm{CI}$ & P-value & HR & $95 \% \mathrm{CI}$ & P-value \\
\hline Sex & 1.520 & $0.891-2.591$ & 0.124 & & & \\
\hline Age (years) & 1.456 & $0.818-2.592$ & 0.202 & & & \\
\hline Family cancer history & 0.739 & $0.431-1.266$ & 0.270 & & & \\
\hline Lymphocyte infiltration & 0.813 & $0.569-1.163$ & 0.257 & & & \\
\hline Vascular tumor cell invasion & 1.294 & $0.831-2.015$ & 0.254 & & & \\
\hline Neoplasm grade & 0.724 & $0.445-1.176$ & 0.191 & & & \\
\hline Pathologic stage & 0.942 & $0.427-2.076$ & 0.882 & & & \\
\hline AFP level (ng/ml) & 0.754 & $0.423-1.345$ & 0.339 & & & \\
\hline Child-Pugh classification grade & 1.099 & $0.421-2.866$ & 0.847 & & & \\
\hline Liver fibrosis Ishak score & 0.915 & $0.572-1.464$ & 0.712 & & & \\
\hline Relapse & 0.619 & $0.385-0.996$ & $0.048^{*}$ & 0.613 & $0.381-0.986$ & $0.044^{*}$ \\
\hline Lin28B expression & 1.377 & $1.033-1.826$ & $0.029^{*}$ & 1.002 & $1.001-1.002$ & $<0.001^{* * *}$ \\
\hline
\end{tabular}

${ }^{*} P<0.05,{ }^{* *} P<0.01,{ }^{* * *} P<0.001$. AFP: $\alpha$-fetoprotein, HR: hazard ratio, CI: confidence interval.

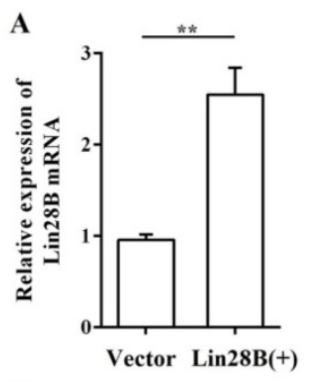

B
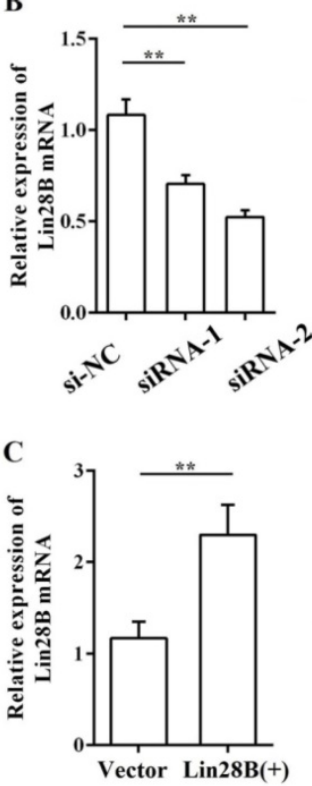
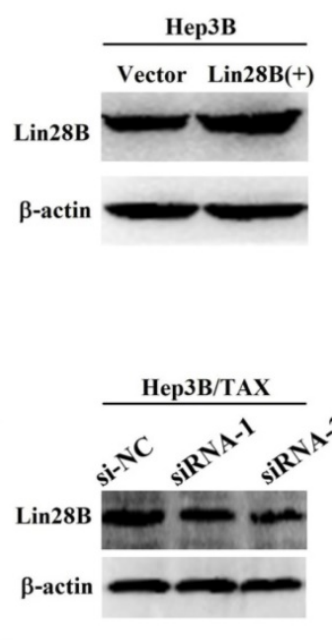

\section{2}

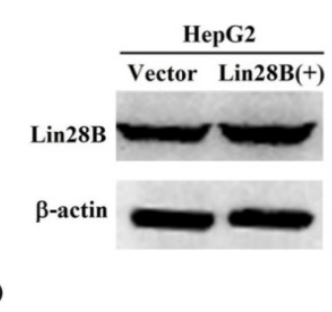

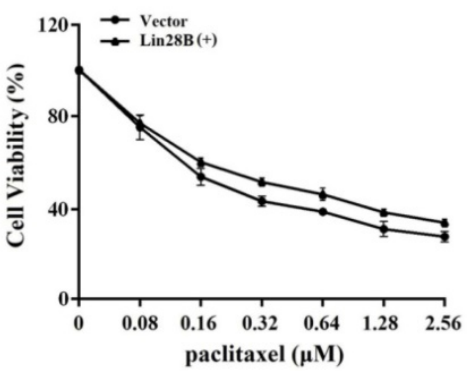
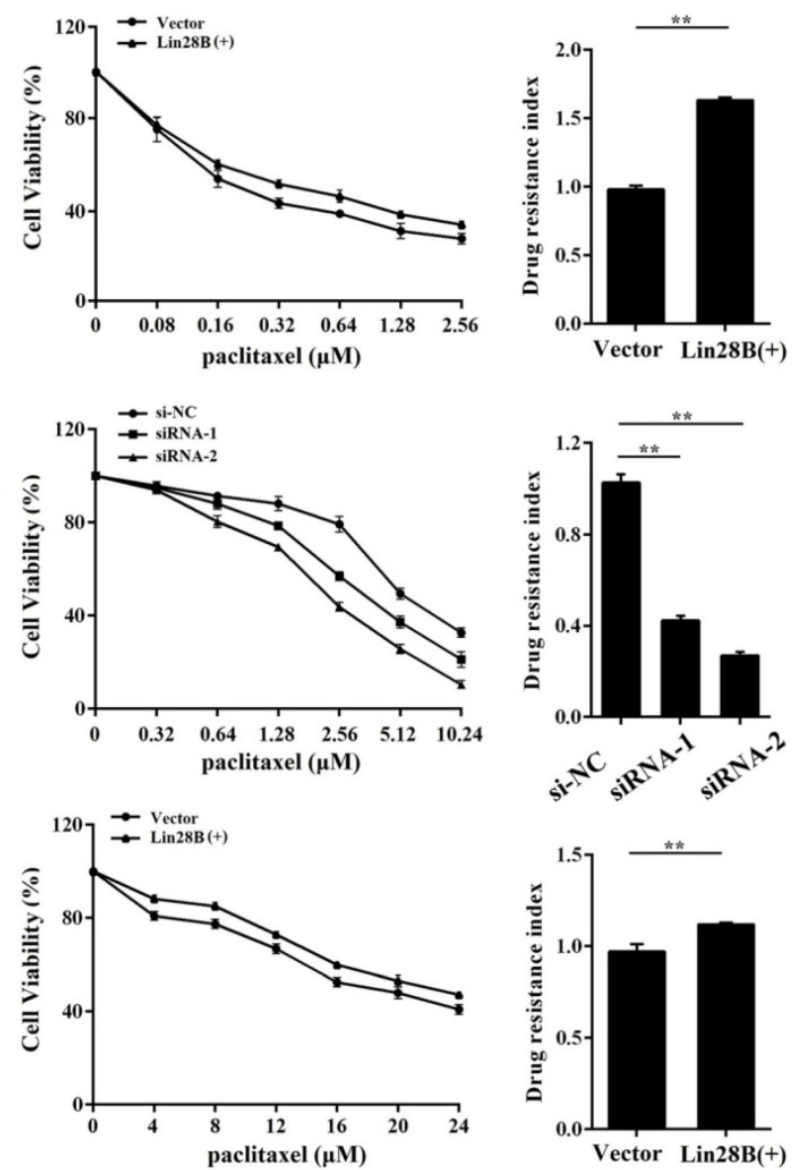

Figure 2. Contribution of Lin28B to paclitaxel resistance in HCC cells. (A) Hep3B cells stably overexpressing Lin28B, (B) Hep3B/TAX cells transfected with Lin28B siRNAs for $48 \mathrm{~h}$, and (C) HepG2 cells stably overexpressing Lin28B were subjected to qRT-PCR, western blot, and the MTT assay. Left, qRT-PCR and western blot to assess Lin28B expression; middle, representative dose-dependent cell viability curves; right, average resistance indexes (RI, the ratio of $I C_{50}$ value of the experimental cells to that of the control cells). Vector, empty vector transfected; Lin28B (+), Lin28B overexpression; si-NC, negative control siRNA; siRNA, Lin28B siRNA; *p <0.05; ** $p<0.01$. 

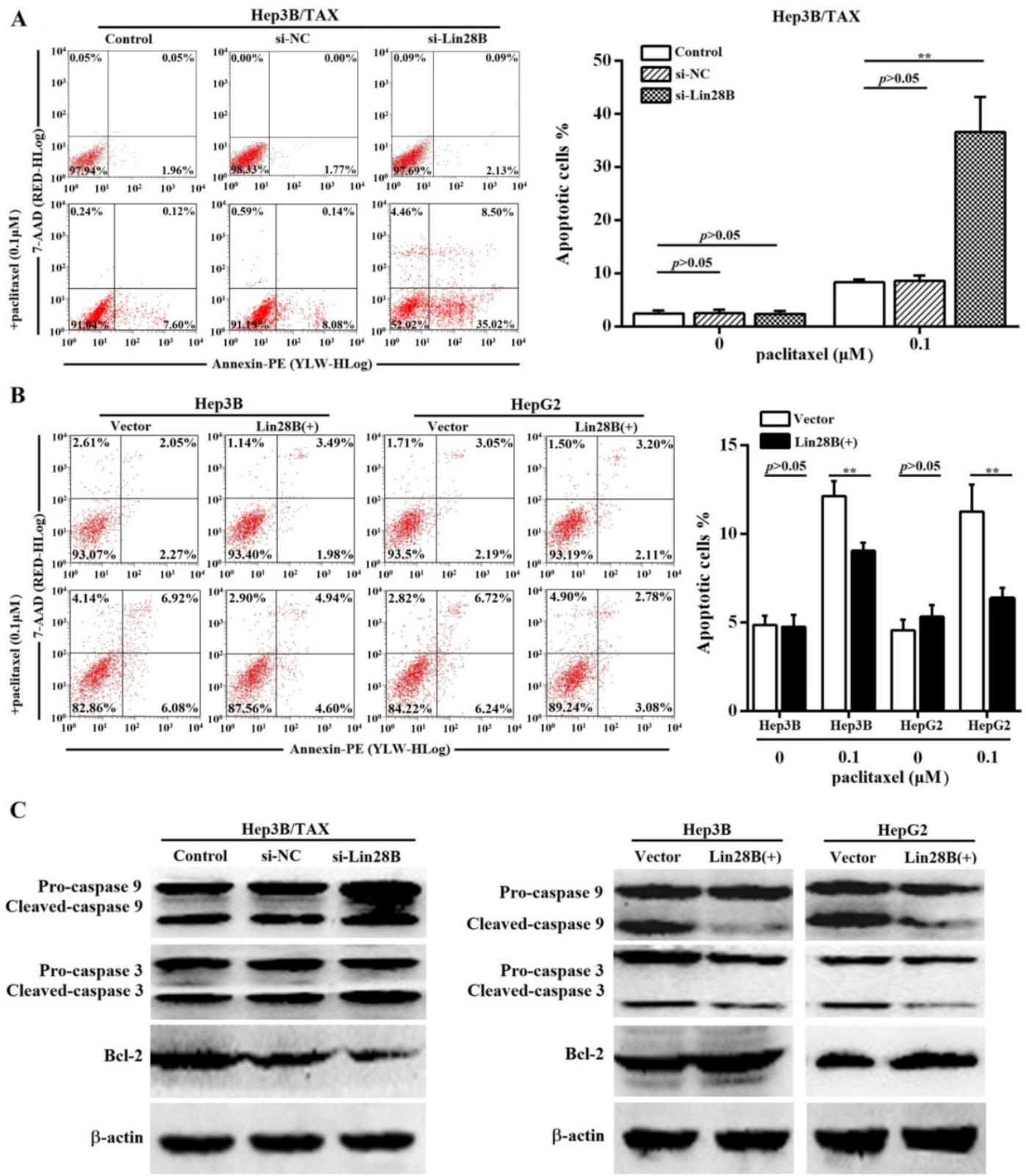

Figure 3. Effect of Lin28B on paclitaxel-induced apoptosis. (A) Hep3B/TAX cells transiently transfected with siRNAs for 48h and (B) Hep3B and HepG2 cells stably overexpressing Lin28B were treated with paclitaxel for $48 \mathrm{~h}$ and apoptosis was analyzed. (C) Western blot of apoptosis-related proteins (caspase 9, caspase 3, and Bcl-2). Vector, empty vector transfected; Lin28B (+), Lin28B overexpression; si-NC, negative control siRNA; si-Lin28B, Lin28B siRNA; $* p<0.05 ; * * p<0.01$.

The inflammatory transcription factor NF-kB has been shown to directly activate Lin28B, and NF-KB is reported to be highly expressed and activated by paclitaxel in several tumor cell lines including Hep3B $[19,35]$. Therefore, we performed a series of experiments to analyze the expression, nuclear translocation, and DNA-binding capacity of NF- $\mathrm{kB}$ in Hep3B/TAX cells. Western blot and IHC staining revealed that co-treatment with curcumin and paclitaxel inhibited NF-KB protein expression more than paclitaxel treatment alone both in vitro and in vivo (Fig. 6B and 6C). The results of immunofluorescence staining (IF) and NF-kB (p65) transcription factor assay showed a significant decrease in NF- $\mathrm{KB}$ translocation and dose-dependent suppression of NF-KB DNA binding in curcumin and paclitaxel co-treated Hep3B/TAX cells (Fig.6D and $6 \mathrm{E})$.

\section{Curcumin inhibits the expression of Lin28B through NF-KB}

Lin28B has been verified to be a target gene of NF-kB [19, 36]. Therefore, we further explored whether curcumin could downregulate the expression of Lin28B through NF-kB. As shown in Fig.7A, The reduction of Lin28B protein level was noticeable in cells treated with 2.5 and $5 \mu \mathrm{M}$ curcumin which coincides with decreased NF-kB expression in the 
cell nuclei. Notably, a lower dose $1.25 \mu \mathrm{M}$ curcumin didn't induce significant change of NF-kB. In concordance, Lin28B protein was not changed significantly either, indicating the correlation among curcumin treatment, NF-KB activity and Lin28B expression. Next, we stimulated Hep3B/TAX cells with $10 \mathrm{ng} / \mathrm{mL}$ tumor necrosis factor-alpha (TNF-a, a classical activator of NF-kB signaling) for $0.5,1$, and 2 $\mathrm{h}$ after a $48 \mathrm{~h}$ curcumin treatment to evaluate whether stimulation of NF-kB abrogated curcumin-inhibited Lin28B expression. As shown in Fig.7B, 7C, and 7D, 10 $\mathrm{ng} / \mathrm{mL}$ TNF-a significantly increased the expression, DNA-binding, and translocation activities of NF- $\mathrm{kB}$ in cell nuclei, which was inhibited by a $48 \mathrm{~h}$ treatment with curcumin. Moreover, curcumin-inhibited Lin28B expression was stimulated by TNF- $\alpha$ in a timedependent manner (Fig.7B and 7C), firmly support the regulatory role of NF- $\mathrm{KB}$ in curcumin-inhibited Lin28B expression. Sequence analysis revealed a highly conserved NF- $\mathrm{kB}$ motif in the first intron of the Lin28B (Iliopoulos D et al. 2009). Therefore, we transient transfected luciferase reporter vector pGL3.0-Lin28B-wt (containing putative NF-kB binding motif) or pGL3.0-Lin28B-mut (containing mutant NF-KB binding motif) in Hep3B/TAX cells (Fig.7E.), respectively. Gene reporter assays revealed that luciferase activity was higher in cells transfected with pGL3.0-Lin28B-wt than those transfected with pGL3.0-Lin28B-mut or empty vector (Fig.7F). Next, we determined whether curcumin has the ability to inhibit the Lin28B expression through reducing the DNA binding activity of NF-KB. To this end, we stimulated pGL3.0-Lin28B-wt or pGL3.0-Lin28B-mut transfected Hep3B/TAX cells with $10 \mathrm{ng} / \mathrm{mL}$ TNF-a for $4 \mathrm{~h}$ after a $48 \mathrm{~h}$ curcumin treatment and found that TNF-a significantly increased the activation of Lin28B promoter activity in pGL3.0-Lin28B-wt transfected but not in pGL3.0-Lin28B-mut transfected Hep3B/TAX cells (Fig.7G). Taken together, these data provided strong evidence that Lin28B promoter activity was downregulated by curcumin treatment through inhibition of NF-KB activity.
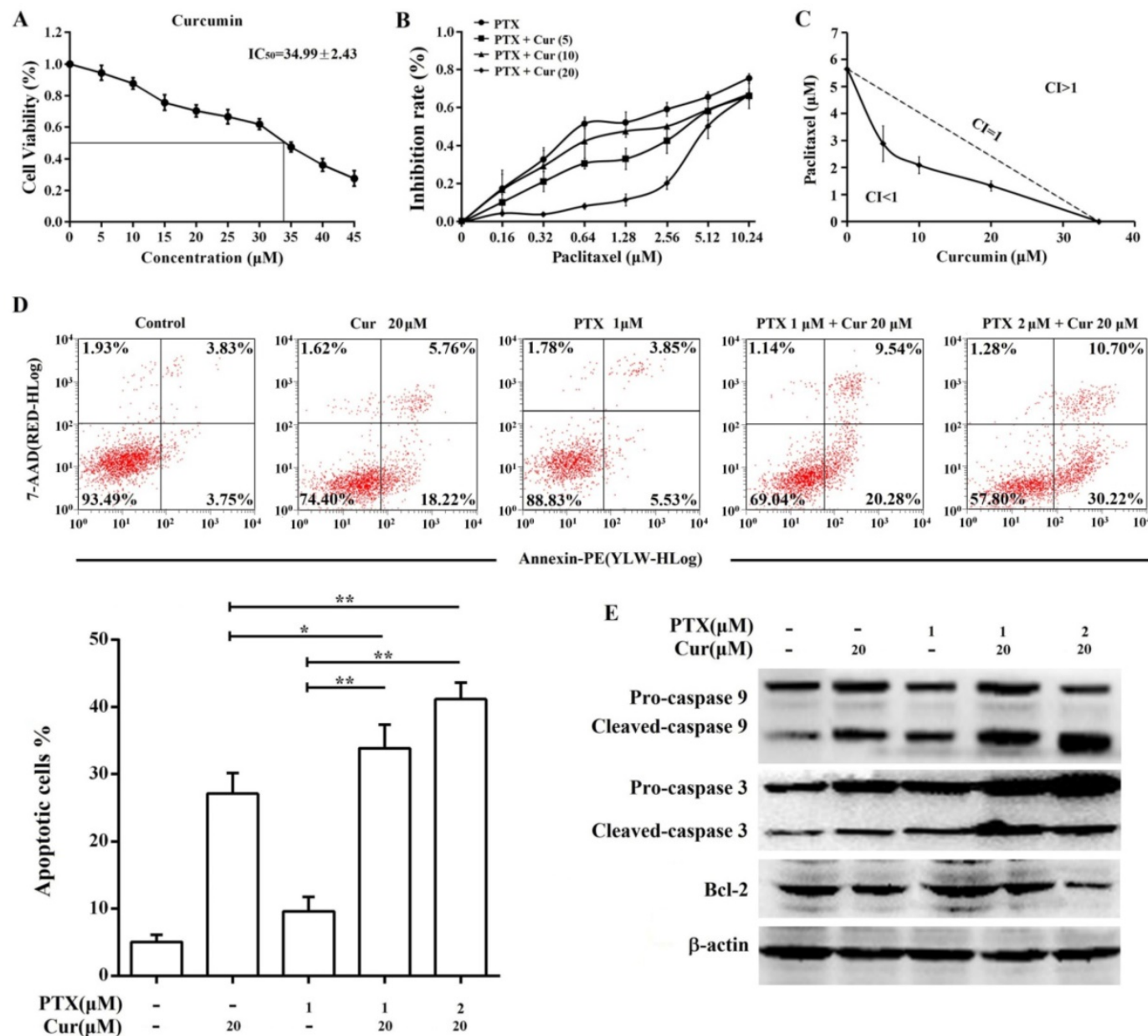

Annexin-PE(YLW-HLog)
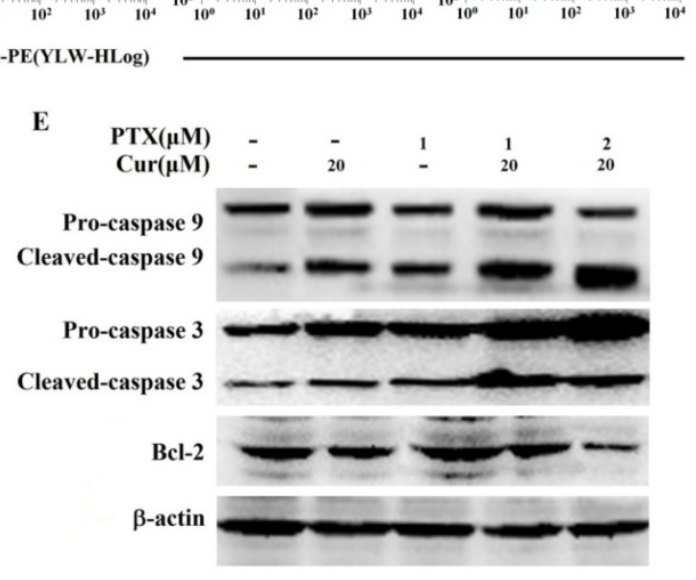

Figure 4.Co-treatment with curcumin and paclitaxel causes cytotoxicity and apoptosis in Hep3B/TAX cells. (A) MTT assay of Hep3B/TAX cells treated with increasing concentrations of curcumin for $48 \mathrm{~h}$. The $\mathrm{IC}_{50}$ value was defined as the dose of the drug required to inhibit cell growth by $50 \%$ and was calculated using the improved Karber's method. (B) Hep3B/TAX cells were treated with $1 \mu \mathrm{M}$ paclitaxel combined with increasing concentrations of curcumin for $48 \mathrm{~h}$, and then cell viability was analyzed by the MTT assay. (C) Isobologram analysis showing the effects of paclitaxel treatment combined with curcumin on Hep3B/TAX cells. Hep3B/TAX cells were stained with Annexin $\mathrm{V}-\mathrm{PE} / 7-\mathrm{AAD}$ and analyzed by (D) flow cytometry and (E) western blot, after treatment with paclitaxel and curcumin individually, or in combination for $48 \mathrm{~h}$. Cur, curcumin; PTX, paclitaxel; * $p<0.05$; ** $p<0.01$. 


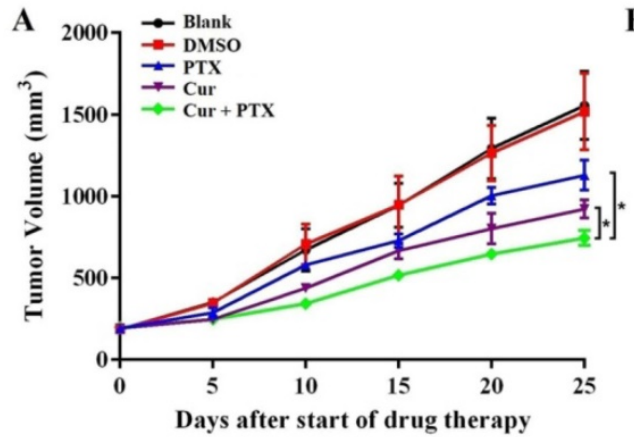

D

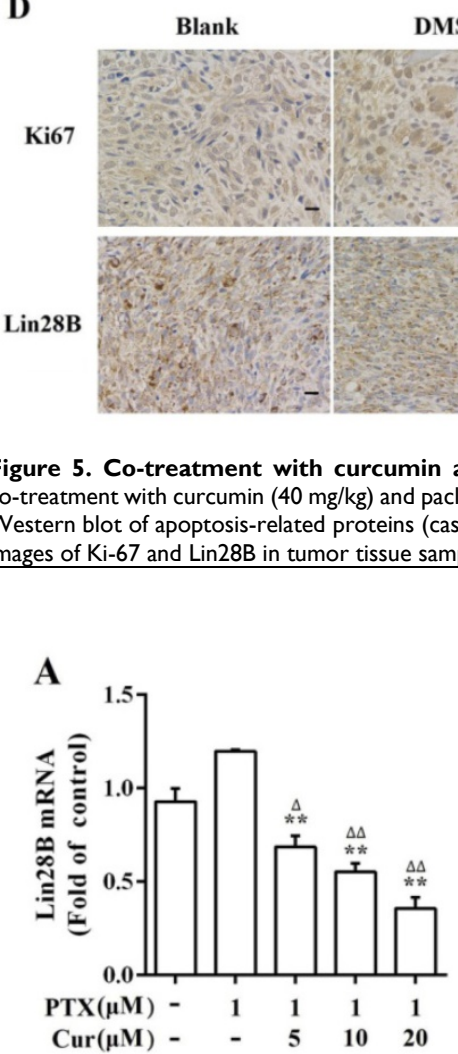

B

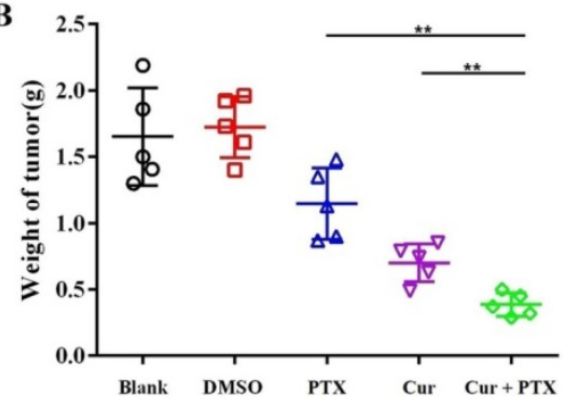

C

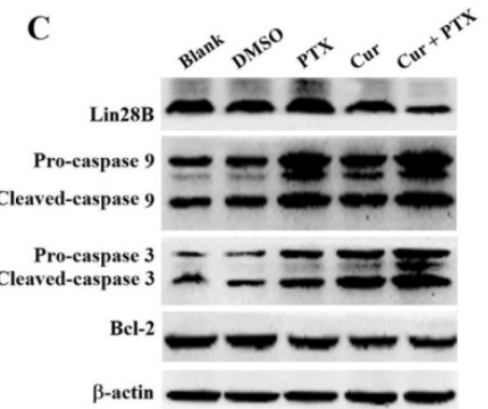

PTX

Cur

Cur + PTX

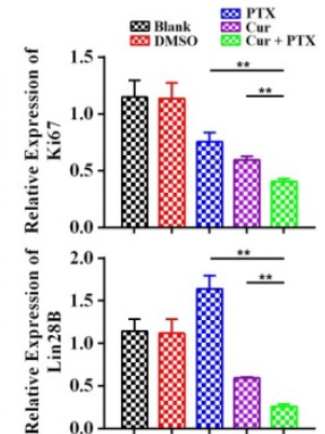

Figure 5. Co-treatment with curcumin and paclitaxel causes cytotoxicity and apoptosis in HCC cells in vivo. (A-B) Analysis of the anti-tumor effects of co-treatment with curcumin $(40 \mathrm{mg} / \mathrm{kg})$ and paclitaxel $(10 \mathrm{mg} / \mathrm{kg})$. Tumor volume is presented as a growth curve, and the tumor weight is presented as a Cleveland dot plot. (C) Western blot of apoptosis-related proteins (caspase 9, 3, and Bcl-2) and Lin28B expression levels in the tumors of the mice. (D) Representative immunohistochemistry (IHC) images of Ki-67 and Lin28B in tumor tissue samples, Scale bar=50 $\mu \mathrm{m} . * p<0.05 ; * * p<0.01$.

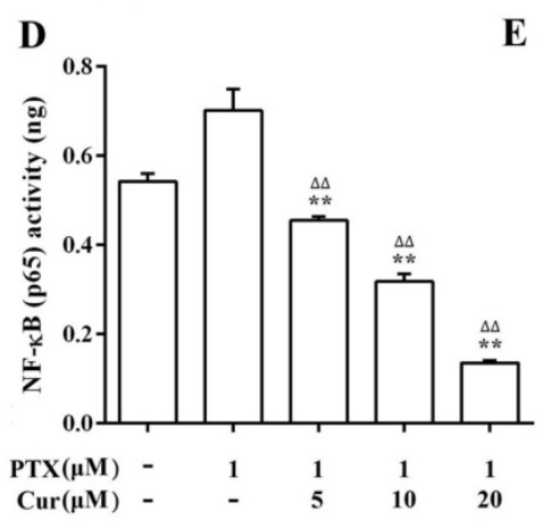

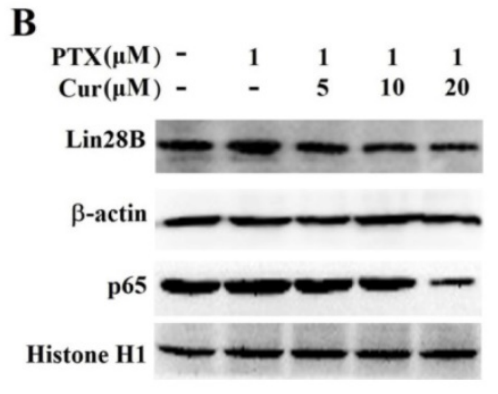

$\mathbf{E}$

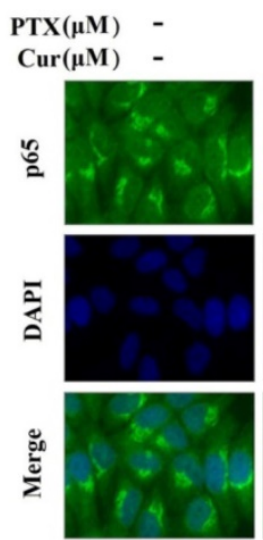

C
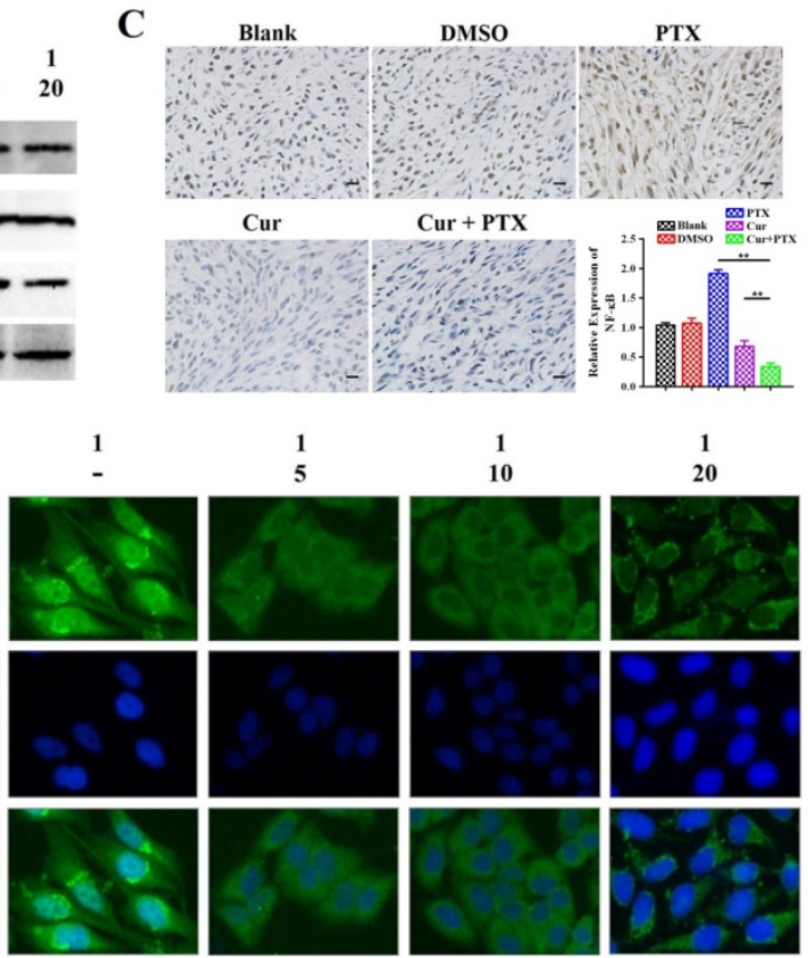

Figure 6. The effect of curcumin on paclitaxel-induced Lin28B and NF-KB levels. (A, B) qRT-PCR and western blot showing Lin28B levels in Hep3B/TAX cells treated with curcumin and paclitaxel alone or in combination.(C) IHC showing NF-KB levels in the nuclear fractions of Hep3B/TAX cells treated with curcumin and paclitaxel alone or in combination, Scale bar $=50 \mu \mathrm{m}$. (D) Hep3B/TAX cells were fixed with $4 \%$ paraformaldehyde and permeabilized with $5 \%$ Triton $X-100$. After blocking the slides with $5 \%$ BSA, they were stained for NF-KB and mounted using DAPI, and images were captured using a Nikon microscope. (E) NF-KB activity was measured using the NF-KB ( $\mathrm{F} 65$ ) Transcription Factor Assay Kit. $* p<0.05, * * p<0.01$ for the control versus paclitaxel groups. $\Delta p<0.05 \Delta \Delta p<0.01$ for paclitaxel versus paclitaxel and curcumin co-treatment groups (Cur, curcumin; PTX, paclitaxel). 

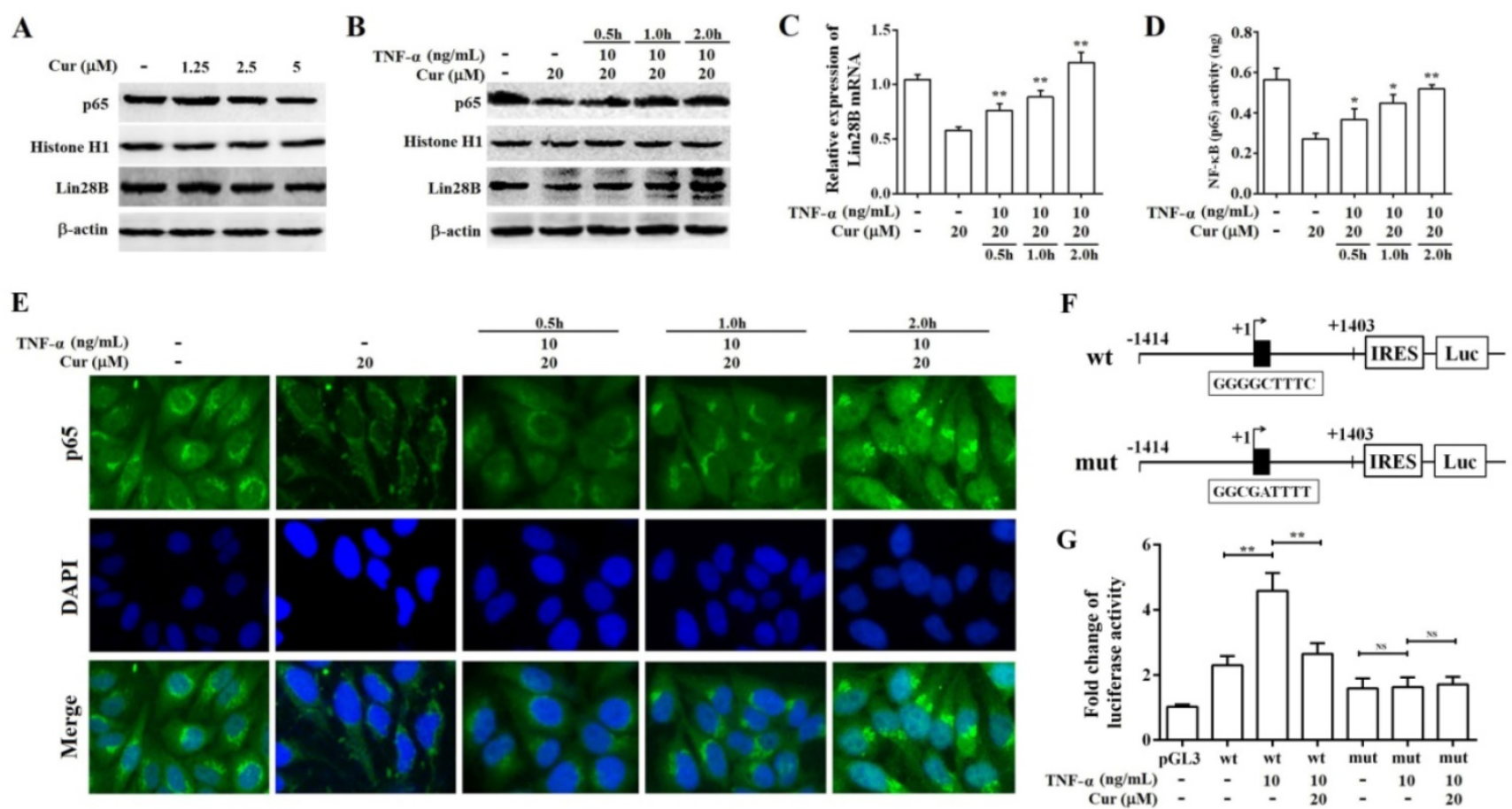

Figure 7. Curcumin inhibits the expression of Lin28B through NF-KB. (A) Western bolt analysis of Lin28B and NF-kB (p65) expression levels in Hep3B/TAX cells after treatment with $1.25,2.5$, and $5 \mu \mathrm{M}$ curcumin for $48 \mathrm{~h}$. (B) Western bolt analysis of Lin28B and NF-KB (p65) expression levels in Hep3B/TAX cells, following stimulation with 10 $\mathrm{ng} / \mathrm{mL}$ TNF- $\alpha$ and a $48 \mathrm{~h}$ curcumin treatment. (C) qRT-PCR analysis of Lin28B in Hep3B/TAX cells stimulated by $10 \mathrm{ng} / \mathrm{mL}$ TNF- $\alpha$ after a $48 \mathrm{~h}$ curcumin treatment. (D) DNA-binding activity of NF-KB (p65) was measured using the NF-KB (p65) Transcription Factor Assay Kit. (E) Immunofluorescence staining was performed, and images were captured using a Nikon microscope. (F) Schematic representation of the human Lin28B promoter region contain in PGL3-Lin28B-wt or PGL3-Lin28B-mut vector. NF-KB binding motifs were shown as black blocks. The sequences of consensus and mutated NF-KB binding motif were shown. (G) Luciferase activity of pGL3-Lin28B-wt, pGL3-Lin28B-mut, or empty vector in Hep3B/TAX cells which were stimulated with or without $10 \mathrm{ng} / \mathrm{mL}$ TNF- $\alpha$ for $4 \mathrm{~h}$ after a $48 \mathrm{~h}$ curcumin treatment. $* p<0.05 * * p<0.01$ for control versus paclitaxel groups, $\Delta p<0.05 \Delta p<0.01$ for paclitaxel versus paclitaxel and curcumin co-treatment groups, NS: Not significant (Cur, curcumin; PTX, paclitaxel).

\section{Discussion}

Several studies have reported the aberrant expression of Lin28B and its association with outcomes in epithelial ovarian cancer, breast cancer, and neuroblastoma. In the present study, we investigated the correlation between Lin28B expression and clinical outcomes in HCC patients as well as its role in the susceptibility of HCC to chemotherapy. The results showed that Lin28B is overexpressed in HCC tissues and is closely associated with a patient's AFP levels, which is used as a diagnostic criterion for HCC. In addition, univariate and multivariate analyses indicated that high Lin28B expression predicts poorer prognosis of HCC patients, and may act as a prognostic biomarker. Cheng et al. [37] demonstrated that, for HCC, Lin28B is associated with a high tumor grade, large size, high American Joint Committee on Cancer (AJCC) stage, high Barcelona-Clinic Liver Cancer (BLCL) stage and recurrence. However, we did not observe a correlation between Lin28B expression and these clinicopathological features. This may be due to a difference in Lin28B assessment methods, as we measured Lin28B levels in the solid tumor, whereas Cheng et al. measured circulating Lin28B levels.

Chemoresistance is a major cause of treatment failure and is an important challenge for cancer therapy [38]. Therefore, identifying the molecular markers of chemoresistance and increasing tumor-cell sensitivity to chemotherapeutic drugs are critical for enhancing therapeutic efficacy. Hsu et al. [39] demonstrated that overexpression of Lin28B was associated with resistance to platinum-based chemotherapy in ovarian cancer. In this study, we found that overexpression of Lin28B significantly increased paclitaxel-induced chemoresistance in Hep3B and HepG2 cells lines, while silencing of Lin28B reduced chemoresistance in Hep3B/TAX cells, indicating that Lin28B contributes to paclitaxelinduced chemoresistance in HCC cells. Paclitaxel has been used to treat a wide range of tumors; its antitumor mechanism involves inhibition of microtubule assembly, which blocks the progression of mitosis and prolonged activation of this mitotic checkpoint triggers apoptosis $[40,41]$. Our results showed that Lin28B inhibited paclitaxel-induced apoptosis in HCC cells and this effect may be related to the regulation of apoptosis-related protein activity. Thus, we speculate that Lin28B may be a useful molecular marker of chemoresistance in HCC.

An effort that deserves attention is a novel combination treatment strategy, that aims to reverse 
chemoresistance through the sequential addition of an adjuvant drug that targets resistance caused by chemotherapy [42]. In our previous study, curcumin was found to sensitize HCC cells to paclitaxel in vitro [43]. In the current study, we use the paclitaxelresistant cell line Hep3B/TAX and a xenograft mouse model to further explore the underlying mechanism of curcumin reversed paclitaxel-induced chemoresistance in HCC. Isobolograms showed a dosedependent cytotoxic effect of paclitaxel on Hep3B/ TAX cells, which was synergistically potentiated by co-treatment with curcumin. An annexin V PE/7-AAD apoptosis assay revealed that induction of apoptosis by paclitaxel in Hep3B/TAX cells was significantly enhanced by curcumin. Similarly, in the Hep3B/TAX-derived xenograft mouse model, we showed that co-treatment with curcumin and paclitaxel not only significantly reduced tumor size but also increased tumor cell apoptosis. Collectively, our findings, from both the in vitro and in vivo assays, provide valuable insights into the beneficial effects of curcumin on paclitaxel-induced chemoresistance in HCC.

Several studies have shown curcumin to be a promising sensitizer to chemotherapeutic agents, including paclitaxel, in a wide variety of tumor cell types [44-49]. Curcumin combined with standard docetaxel chemotherapy led to a significant improvement and clinical response in patients with metastatic breast cancer in a phase I clinical trial [50]. Considering the pleiotropic activity of curcumin in

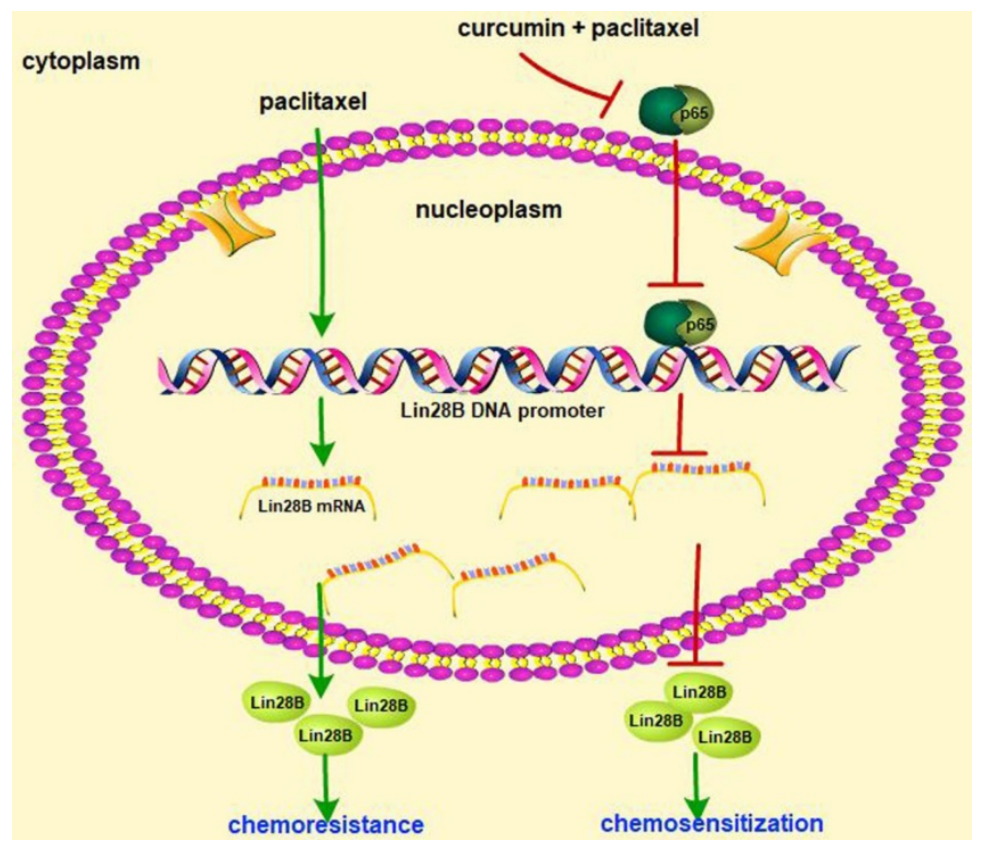

Figure 8. Schematic of paclitaxel-induced chemoresistance involving Lin28B and the chemosensitizing effect of curcumin in HCC cells. Paclitaxel treatment of HCC cells upregulated Lin28B expression and induced chemoresistance, whereas co-treatment with curcumin and paclitaxel downregulated Lin28B expression by inhibiting the activity of NF-KB. cancer prevention, it could be involved in chemosensitization in several different ways, such as inhibition of NF-kB signaling [47], miRNA-induced suppression of cell proliferation [48], and modulation of epidermal growth factor receptor (EGFR) signaling [49]. Our results showed that Lin28B expression in Hep3B/TAX cells and xenograft tumor tissue was significantly decreased in a dose-dependent manner following co-treatment with curcumin and paclitaxel. These results indicate that curcumin exhibits its paclitaxel-sensitizing effect by reducing of Lin28B expression in HCC.

Experiments involving sequence analysis combined with chromatin immunoprecipitation assay conducted in Kevin Struhl's laboratory [19] revealed a highly conserved NF- $\mathrm{KB}$ motif in the first intron of the $\operatorname{Lin} 28 B$ gene, indicating that NF- $\kappa B$ activates $\operatorname{Lin} 28 B$ expression through direct binding. NF- $\mathrm{kB}$, which is an important transcription factor for immunity, inflammation, and cell survival and is a hallmark of tumorigenesis [50], typically exists as a heterodimer composed of the Rel-family proteins p50 and p65 (RelA). In cancer, NF- $\mathrm{KB} / \mathrm{p} 65$ regulates the transcription of growth-promoting and anti-apoptotic genes. Given the fact that curcumin has a potential to disrupt several steps of the NF-kB activation pathway, we further investigated the function of NF-kB/p65 in curcumin-inhibited Lin28B expression. Using the NF- $\mathrm{kB}$ signaling activator TNF- $\mathrm{a}$, we found that curcumin-inhibited Lin28B expression was stimulated by TNF- $\alpha$ in a time-dependent manner, suggesting the regulatory role of NF-KB in curcumin-inhibited Lin28B expression. Additionally, the results of luciferase reporter assays shown that mutation of the binding site of NF-KB in Lin28B promoter region abrogated the inhibitory effects of curcumin on Lin $28 \mathrm{~B}$ promoter activity. These data further reinforces the finding that curcumin inhibits the expression of Lin28B through NF- $\mathrm{KB}$ in Hep3B/TAX cells.

\section{Conclusions}

Our data demonstrate that Lin28B is upregulated in paclitaxel-resistant HCC cells, and Lin28B overexpression results in paclitaxel resistance, while silencing Lin28B increased the sensitivity of to paclitaxel. Curcumin sensitized cells to paclitaxelinduced chemoresistance by inhibiting Lin28B and the upstream protein NF-KB (Fig. 8). Moreover, upregulation of Lin28B is associated with poor prognosis in patients with HCC. Thus, Lin28B may serve as a predictive biomarker for use in the 
development of personalized treatment strategies and as a treatment target to reverse chemoresistance in clinical practice.

\section{Abbreviations}

AFP: $\alpha$-fetoprotein; AJCC: American Joint Committee on Cancer; BLCL: Barcelona-Clinic Liver Cancer; CI: combination index; DMEM: Dulbecco's modified Eagle's medium; DMSO: dimethyl sulfoxide; EGFR: epidermal growth factor receptor; ES: embryonic stem; FBS: fetal calf serum; GEO: Gene Expression Omnibus; HCC: hepatocellular carcinoma; HR: hazards ratio; IF: Immunofluorescent staining; IHC: Immunohistochemistry; LIHC: liver hepatocellular carcinoma; Oct4: octamer-binding transcription factor 4; OS: overall survival; PFS: progressionfree survival; RI: resistance index; Sox2: sex determining region $\mathrm{Y}$ box 2; TCGA: The Cancer Genome Atlas; TNF-a: tumor necrosis factor-alpha.

\section{Acknowledgements}

This study was supported in part by research fund for National Natural Science Foundation of China (81602624), Natural Science Foundation of Zhejiang Province (LY16H290001, LY14H290007).

\section{Competing Interests}

The authors have declared that no competing interest exists.

\section{References}

1. Forner A, Llovet JM, Bruix J. Hepatocellular carcinoma. Lancet. 2012; 379: 1245-55.

2. Chen W, Zheng R, Baade PD, Zhang S, Zeng H, Bray F, et al. Cancer statistics in China, 2015. CA Cancer J Clin. 2016; 66: 115-32.

3. Nagano $\mathrm{H}$. Treatment of advanced hepatocellular carcinoma: intraarterial infusion chemotherapy combined with interferon. Oncology. 2010; 78 Suppl 1: 142-7.

4. Wu L, Pan C, Wei X, Shi $Y$, Zheng J, Lin X, et al. IncRNA KRAL reverses 5-fluorouracil resistance in hepatocellular carcinoma cells by acting as a ceRNA against miR-141. Cell Commun Signal. 2018; 16: 47.

5. Lin M, Lv D, Zheng Y, Wu M, Xu C, Zhang Q, et al. Downregulation of CPT2 promotes tumorigenesis and chemoresistance to cisplatin in hepatocellular carcinoma. Onco Targets Ther. 2018; 11: 3101-10.

6. Huang $H$, Chen J, Ding CM, Jin X, Jia ZM, Peng J. LncRNA NR2F1-AS1 regulates hepatocellular carcinoma oxaliplatin resistance by targeting $\mathrm{ABCC} 1$ via miR-363. J Cell Mol Med. 2018; 22: 3238-45.

7. Li B, Zhao S, Geng R, Huo Z, Zhang H. The Sineoculis Homeobox Homolog 1 (SIX1) Gene Regulates Paclitaxel Resistance by Affecting Reactive Oxygen Species and Autophagy in Human Hepatocellular Carcinoma Cell Line HepG2. Med Sci Monit. 2018; 24: 2271-9.

8. Ambros V, Horvitz HR. Heterochronic mutants of the nematode Caenorhabditis elegans. Science. 1984; 226: 409-16.

9. Moss EG, Lee RC, Ambros V. The cold shock domain protein LIN-28 controls developmental timing in C. elegans and is regulated by the lin-4 RNA. Cell. 1997; 88: 637-46.

10. Wang $T$, Wang $G$, Hao $D$, Liu $X$, Wang $D$, Ning $N$, et al Aberrant regulation of the LIN28A/LIN28B and let-7 loop in human malignant tumors and its effects on the hallmarks of cancer. Mol Cancer. 2015; 14: 125

11. Lin $X$, Shen J, Dan Peng, He X, Xu C, Chen X, et al. RNA-binding protein LIN28B inhibits apoptosis through regulation of the AKT2/FOXO3A/BIM axis in ovarian cancer cells. Signal Transduct Target Ther. 2018; 3: 23.

12. Xu B, Zhang K, Huang Y. Lin 28 modulates cell growth and associates with a subset of cell cycle regulator mRNAs in mouse embryonic stem cells. RNA. 2009; 15: 357-61

13. Darr $\mathrm{H}$, Benvenisty N. Genetic analysis of the role of the reprogramming gene LIN-28 in human embryonic stem cells. Stem Cells. 2009; 27: 352-62.
14. Yu J, Vodyanik MA, Smuga-Otto K, Antosiewicz-Bourget J, Frane JL, Tian S, et al. Induced pluripotent stem cell lines derived from human somatic cells. Science. 2007; 318: 1917-20.

15. Guo Y, Chen Y, Ito H, Watanabe A, Ge X, Kodama T, et al. Identification and characterization of lin-28 homolog B (LIN28B) in human hepatocellular carcinoma. Gene. 2006; 384: 51-61.

16. Kugel S, Sebastián C, Fitamant J, Ross KN, Saha SK, Jain E, et al. SIRT6 suppresses pancreatic cancer through control of Lin28b. Cell. 2016; 165: 1401-15.

17. Schnepp RW, Khurana P, Attiyeh EF, Raman P, Chodosh SE, Oldridge DA, et al. A LIN28B-RAN-AURKA signaling network promotes neuroblastoma tumorigenesis. Cancer Cell. 2015; 28: 599-609.

18. Beachy SH, Onozawa M, Chung YJ, Slape C, Bilke S, Francis P, et al. Enforced expression of Lin28b leads to impaired T-cell development, release of inflammatory cytokines, and peripheral T-cell lymphoma. Blood. 2012; 120: 1048-59.

19. Iliopoulos D, Hirsch HA, Struhl K. An epigenetic switch involving NF-kappaB, Lin28, Let-7 MicroRNA, and IL6 links inflammation to cell transformation. Cell. 2009; 139: 693-706.

20. Ma L, Zhao Q, Chen W, Zhang Y. Oncogene Lin28B increases chemosensitivity of colon cancer cells in a let-7-independent manner. Oncol Lett. 2018; 15: 6975-81.

21. Rao S, Lee SY, Gutierrez A, Perrigoue J, Thapa RJ, Tu Z, et al. Inactivation of ribosomal protein $\mathrm{L} 22$ promotes transformation by induction of the stemness factor, Lin28B. Blood. 2012; 120: 3764-73.

22. Molenaar JJ, Domingo-Fernández R, Ebus ME, Lindner S, Koster J, Drabek $\mathrm{K}$, et al. LIN28B induces neuroblastoma and enhances MYCN levels via let-7 suppression. Nat Genet. 2012; 44: 1199-206.

23. Madison BB, Liu Q, Zhong X, Hahn CM, Lin N, Emmett MJ, et al. LIN28B promotes growth and tumorigenesis of the intestinal epithelium via Let-7. Genes Dev. 2013; 27: 2233-45.

24. Urbach A, Yermalovich A, Zhang J, Spina CS, Zhu H, Perez-Atayde AR, et al. Lin28 sustains early renal progenitors and induces Wilms tumor. Genes Dev. 2014; 28: 971-82.

25. Nguyen LH, Robinton DA, Seligson MT, Wu L, Li L, Rakheja D, et al. Lin28b is sufficient to drive liver cancer and necessary for its maintenance in murine models. Cancer Cell. 2014; 26: 248-61.

26. Permuth-Wey J, Kim D, Tsai YY, Lin HY, Chen YA, Barnholtz-Sloan J, et al. LIN28B polymorphisms influence susceptibility to epithelial ovarian cancer. Cancer Res. 2011; 71: 3896-903.

27. Diskin SJ, Capasso M, Schnepp RW, Cole KA, Attiyeh EF, Hou C, et al. Common variation at $6 \mathrm{q} 16$ within HACE1 and LIN28B influences susceptibility to neuroblastoma. Nat Genet. 2012; 44: 1126-30.

28. Chen AX, Yu KD, Fan L, Li JY, Yang C, Huang AJ, et al. Germline genetic variants disturbing the Let-7/LIN28 double-negative feedback loop alter breast cancer susceptibility. PLoS Genet. 2011; 7: e1002259.

29. Panella M, Mosca N, Di Palo A, Potenza N, Russo A. Mutual suppression of miR-125a and Lin28b in human hepatocellular carcinoma cells. Biochem Biophys Res Commun. 2018; 500: 824-7.

30. Liang L, Wong CM, Ying Q, Fan DN, Huang S, Ding J, et al. MicroRNA-125b suppressesed human liver cancer cell proliferation and metastasis by directly targeting oncogene LIN28B2. Hepatology. 2010; 52: 1731-40.

31. You X, Liu F, Zhang T, Lv N, Liu Q, Shan C, et al. Hepatitis B virus X protein upregulates Lin28A/Lin28B through Sp-1/c-Myc to enhance the proliferation of hepatoma cells. Oncogene. 2014; 33: 449-60.

32. Marquardt JU, Gomez-Quiroz L, Arreguin Camacho LO, Pinna F, Lee $\mathrm{YH}$, Kitade $\mathrm{M}$, et al. Curcumin effectively inhibits oncogenic NF-KB signaling and restrains stemness features in liver cancer. J Hepatol. 2015; 63: 661-9.

33. Hu $\mathrm{P}, \mathrm{Ke} \mathrm{C}$, Guo $\mathrm{X}$, Ren $\mathrm{P}$, Tong $\mathrm{Y}$, Luo $\mathrm{S}$, et al. Both glypican-3/Wnt/ $\beta$-catenin signaling pathway and autophagy contributed to the inhibitory effect of curcumin on hepatocellular carcinoma. Dig Liver Dis. 2018; pii: S1590-8658(18)30799-0.

34. Agarwal D, Sharma M, Dixit SK, Dutta RK, Singh AK, Gupta RD, et al. In vitro synergistic effect of fluoroquinolone analogues in combination with artemisinin against Plasmodium falciparum; their antiplasmodial action in rodent malaria model. Malar J. 2015; 14: 48.

35. Shuang T, Wang M, Zhou Y, Shi C, Wang D. NF-kB1, c-Rel, and ELK1 inhibit miR-134 expression leading to TAB1 upregulation in paclitaxel-resistant human ovarian cancer. Oncotarget. 2017; 8: 24853-68.

36. Zhou J, Chooi JY, Ching YQ, Quah JY, Toh SH, Ng Y, et al. NF-kB promotes the stem-like properties of leukemia cells by activation of LIN28B. World J Stem Cells. 2018; 10: 34-42.

37. Cheng SW, Tsai HW, Lin YJ, Cheng PN, Chang YC, Yen CJ, et al. Lin28B is an oncofetal circulating cancer stem cell-like marker associated with recurrence of hepatocellular carcinoma. PLoS One. 2013; 8:e80053.

38. Kim DW, Talati C, Kim R. Hepatocellular carcinoma (HCC): beyond sorafenib-chemotherapy. J Gastrointest Oncol. 2017; 8: 256-65.

39. Hsu KF, Shen MR, Huang YF, Cheng YM, Lin SH, Chow NH, et al. Overexpression of the RNA-binding proteins Lin28B and IGF2BP3 (IMP3) is associated with chemoresistance and poor disease outcome in ovarian cancer. Br J Cancer. 2015; 113: 414-24.

40. Bharadwaj $\mathrm{R}, \mathrm{Yu} \mathrm{H}$. The spindle checkpoint, aneuploidy, and cancer. Oncogene. 2004; 23: 2016-27. 
41. Brito DA, Yang Z, Rieder CL. Microtubules do not promote mitotic slippage when the spindle assembly checkpoint cannot be satisfied. J Cell Biol. 2008; 182: 623-9.

42. Yap TA, Omlin A, de Bono JS. Development of therapeutic combinations targeting major cancer signaling pathways. J Clin Oncol. 2013; 31: 1592-605.

43. Zhou M, Li Z, Han Z, Tian N. Paclitaxel-sensitization enhanced by curcumin involves down-regulation of nuclear factor-kB and Lin28 in Hep3B cells. J Recept Signal Transduct Res. 2015; 35: 618-25.

44. Kumar P, Barua CC, Sulakhiya K, Sharma RK. Curcumin Ameliorates Cisplatin-Induced Nephrotoxicity and Potentiates Its Anticancer Activity in SD Rats: Potential Role of Curcumin in Breast Cancer Chemotherapy. Front Pharmacol. 2017; 8: 132.

45. Zhang P, Lai ZL, Chen HF, Zhang M, Wang A, Jia T, et al. Curcumin synergizes with 5-fluorouracil by impairing AMPK/ULK1-dependent autophagy, AKT activity and enhancing apoptosis in colon cancer cells with tumor growth inhibition in xenograft mice. J Exp Clin Cancer Res. 2017; 36: 190.

46. Zou J, Zhu L, Jiang X, Wang Y, Wang Y, Wang X, et al. Curcumin increases breast cancer cell sensitivity to cisplatin by decreasing FEN1 expression. Oncotarget. 2018; 9: 11268-78.

47. Dang YP, Yuan XY, Tian R, Li DG, Liu W. Curcumin improves the paclitaxel-induced apoptosis of HPV-positive human cervical cancer cells via the NF-kB-p53-caspase-3 pathway. Exp Ther Med. 2015; 9: 1470-6.

48. Lu Y, Wang J, Liu L, Yu L, Zhao N, Zhou X, et al. Curcumin increases the sensitivity of Paclitaxel-resistant NSCLC cells to Paclitaxel through microRNA-30c-mediated MTA1 reduction. Tumour Biol. 2017; 39: 1010428317698353

49. Zhan Y, Chen Y, Liu R, Zhang H, Zhang Y. Potentiation of paclitaxel activity by curcumin in human breast cancer cell by modulating apoptosis and inhibiting EGFR signaling. Arch Pharm Res. 2014; 37: 1086-95.

50. Bayet-Robert M, Kwiatkowski F, Leheurteur M, Gachon F, Planchat E, Abrial $\mathrm{C}$, et al. Phase I dose escalation trial of docetaxel plus curcumin in patients with advanced and metastatic breast cancer. Cancer Biol Ther. 2010; 9: 8-14. 